as 1959. This long gap is explained by the extensive revision and pruning of the book in bringing it up to date. The authors have been able to condense a considerable amount of clinical information into a comparatively small volume. The diseases of the eye and adnexa are considered in detail, with their treatment, and the essential features of anatomy and physiology are also included.

Unfortunately, there are many mistakes in the crossreferences to figures, e.g. on page 146 the reader is referred to Fig. 299 for an undine, while, in fact, this figure is that of a Maddox rod. Also, Plate XXIII is not labelled, making it incomprehensible to an undergraduate.

This is perhaps minor criticism of a practical book which is read the world over by medical students and practising ophthalmologists. It can be recommended for D.O. students, and those sitting for the Fellowship will find it useful as a short survey of the subject.

\section{Diagnostic Methods}

Ed. by J. W. Mills. Pp. 176. London: Butterworths, 1968. $£ 15$ s.

We are told that this little book is primarily designed for the senior nursing staff and house officers in diagnostic methods performed at the bed side. I doubt very much if this aim is achieved. There are seven chapters (chemical pathology, bacteriology, haematology, nuclear medicine, diagnostic radiology, measurement of lung functions, and electro-encephalography and electromyography) written by different authors, and at the end of each chapter there is a short list of suggested titles for further reading.

I wish I could praise this book. The range of subject matter is wide, and the information about each of them is meagre and it gives an impression that seven papers, written by different individuals, are joined together to form a book.

The chapter on diagnostic radiology is comprehensive. The book may serve a limited purpose on a Sister's desk, in a Medical or Surgical Ward, but I doubt it.

\section{The Principles and Practice of Medicine}

Ed. by A. M. Harvey, L. E. Cluff, R. J. Johns, H. H. OWens, D. Rabinowitz and R. S. Ross, with fifty-nine contributors. Seventeenth edition. Pp. xxiii +1473 , illustrated. New York: Appleton-Century-Crofts; London: Butterworths, 1968. $£ 718 \mathrm{~s}$.

This Seventeenth revised edition of this famous book is a different type of textbook on medicine. It does not deal with disease entities, but it attempts to describe and define the way in which an experienced physician approaches the clinical problems. It is edited by six Professors at the John Hopkins University School of Medicine, with the help of fifty-nine contributors, the majority of whom hold faculty appointments at the same University.

The whole subject matter is divided into nineteen sections and each section is made up of chapters, written very comprehensively by different authors. As teachers of Medicine, all the contributors employ with success their knowledge and experience, and scientific facts in different fields of Medicine are presented with admirable clarity.

When teachers from any famous University get together to produce a book, one expects it to be brilliant and informative in form and substance. Brilliant and informative are the correct adjectives for this book and any one who can afford the price should buy it at once. It will enrich his knowledge and help his patients.

\section{Vertebral Manipulation}

By G. D. Maitland. Second edition. Pp. 179, illustrated. London: Butterworths, 1968. $£ 48$ s.

This is a very good reference book with excellent explanatory diagrams and stresses the importance of a thorough knowledge of anatomy. The difference between 'mobilization' and 'manipulation' is explained at length, both in the section dealing with techniques and again under application.

$\mathrm{Mr}$ Maitland is obviously given a fairly free hand in deciding what form of physiotherapy is most likely to be beneficial to the patient. Many departments in this country are not so well placed! He has made an intensive study of the techniques he describes and practises them with acknowledged success. So long as manipulation is kept in perspective as one form of physiotherapy, and not the "cure-all' once advertised by the unqualified bone-setters, it can play a most useful part in the treatment of spinal disorders.

This book can be recommended to both medical practitioners and physiotherapists who have to deal with patients presenting many of the symptoms described. There is great deal of thought-inducing material in it of interest to both 'pros' and 'cons'.

\section{High Blood Pressure}

By Sir George Pickering. Second edition. Pp. viii +717 illustrated. London: J. \& A. Churchill, 1968. £6.

So much has been written about hypertension in the last 12 years since the publication of the first edition of this book that the author has been compelled to abandon the original comprehensive plan and to be more selective in choosing subject matter. During this period, important improvements in the treatment of hypertension have been introduced which, by modifying the natural history of the untreated disease, have thrown new light on our understanding of some of its features. There is now general agreement that provided the renal vessels are not too severely damaged, the malignant phase of hypertension can be abolished by adequate and permanent treatment with hypotensive drugs with consequent greatly improved prognosis. Another change that has followed improved treatment has been that myocardial infarction instead of cerebro-vascular accidents or congestive heart failure is becoming the commonest cause of death in treated patients.

$\mathrm{New}$, also, is the chapter on the complications of hypertension related to three different pathological changes in the arterial tree: namely the fibrinoid necrosis of small arteries and arterioles seen in the malignant phase; miliary cerebral aneurysms which may rupture and cause cerebral haemorrhage; and nodular arteriosclerosis (atheroma) which is the cause of myocardial and cerebral infarction. The role of the platelet thrombus in the development of the atheromatus plaque is discussed and special reference made to embolization of the retinal arteries by platelet thrombi whose passage through the arterial tree can be watched.

In the preface the author says that he wishes to avoid being tedious or dull and in this scholarly work he has fully succeeded. The warmth of conviction with which he argues his case on matters over which there is considerable difference of opinion, together with clarity of his logic, make the book both easy and absorbing to read. In his approach to therapy it is perhaps typical of the book that on a page outlining general treatment of high blood pressure, the words 'common sense' appear as the page title, a philosophy which may be said to pervade the whole of this interesting and authoritative book.

\section{Liver Biopsy Interpretation}

By Peter Scheuer. Pp. 138, illustrated. London: Baillière, Tindall \& Cassell, 1968. 14 5s.

Liver biopsy, with the introduction of the Menghini technique, has become safe provided attention is paid to the prothrombin time and platelet count. However, interpretation of the sometimes small or fragmented pieces may be difficult. In this book Dr Peter Scheuer has brought the expertise gained from experience of many hundreds of biopsies to the general pathologist. He more than succeeds and although he states that no attempt has been made to 